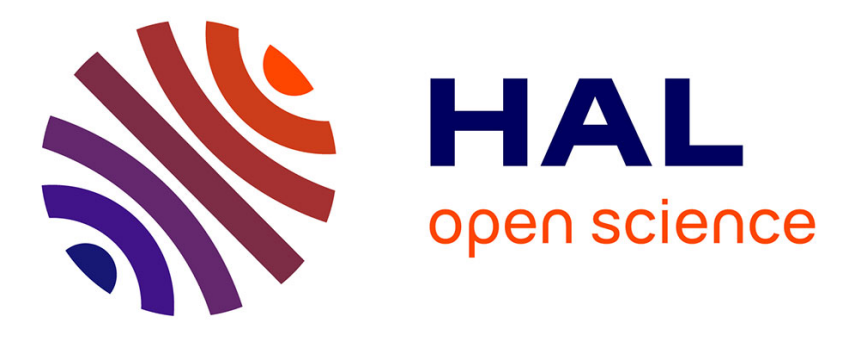

\title{
New Topology of Direct Current Claw-Pole machines for Stop-Start application
}

\author{
Sara Bazhar, Baptiste Ristagno, Julien Fontchastagner, Noureddine \\ Takorabet, Nicolas Labbe
}

\section{- To cite this version:}

Sara Bazhar, Baptiste Ristagno, Julien Fontchastagner, Noureddine Takorabet, Nicolas Labbe. New Topology of Direct Current Claw-Pole machines for Stop-Start application. COMPEL: The International Journal for Computation and Mathematics in Electrical and Electronic Engineering, 2018, 37 (5), pp.1635 - 1644. 10.1108/COMPEL-12-2017-0542 . hal-01914910

\section{HAL Id: hal-01914910 https://hal.science/hal-01914910}

Submitted on 7 Nov 2018

HAL is a multi-disciplinary open access archive for the deposit and dissemination of scientific research documents, whether they are published or not. The documents may come from teaching and research institutions in France or abroad, or from public or private research centers.
L'archive ouverte pluridisciplinaire HAL, est destinée au dépôt et à la diffusion de documents scientifiques de niveau recherche, publiés ou non, émanant des établissements d'enseignement et de recherche français ou étrangers, des laboratoires publics ou privés. 


\title{
New Topology of Direct Current Claw-Pole machines for Stop-Start application
}

\author{
Sara Bazhar, Baptiste Ristagno, Julien Fontchastagner and Noureddine Takorabet \\ Université de Lorraine - GREEN, Vandoeuvre-lès-Nancy, France \\ Nicolas Labbe \\ Valeo Electric Systems, Saint Quentin Fallavier, France
}

\begin{abstract}
Purpose - This paper proposes a new topology of Direct Current (DC) machine using Claw-Pole stator to replace standard DC starter in micro-hybrid vehicles. The main interest of such a topology is the reduction of copper volume.

Design/Methodology/Approach - The design of the claw pole machine is based on a multi-objective optimization of several topologies, based on a three-dimensional (3D) reluctance network modeling. The 3D finite element (FE) model is used to check the results of the optimization and a prototype is manufactured and tested with satisfactory results.

Finding - The claw pole topology with wave-shape windings allows to replace the current DC series classical starter thanks to its copper volume saving.

Research limitations implications - This model is only limited to the optimization of the Claw-Pole stator for a fixed geometry of the rotor.

Originality/Value - The paper deals with a new DC machine topology to reduce the copper volume through the suppression of the classical stator end-windings. The use of Claw-Pole inductors ensures this copper reduction.
\end{abstract}

Keywords - claw-pole machine; permeance network; finite element; optimization

\section{Introduction}

In automotive applications, emission performance standards and industrial competition require the change of electrical machines technology used in some devices such as starters. Indeed, the actual starters are equipped with a standard seriesexcited DC machine. This type of machine is advantageous for its high torque density, but suffers from its high manufacturing cost compared to separately-excited DC machine using ferrites magnets in the stator.

In order to reduce the electrical machines manufacturing costs while maintaining their performances, several authors (ELRefaie, et al, 2011; Spargo et al, 2015; Cros et al., 2001, Rebhi et al. 2012, Felicetti et al. 2003 ) have proposed to reduce the end-coils through the use of different windings types. One mean to reduce copper volume in the excitation coil consists in using a cylindrical coil, as in synchronous claw-pole machines found in automotive alternators (Espanet, 1999). This idea can be adapted to define a new topology of DC machine. In this case, the claw-pole principle is applied in the stator to reduce copper volume. The challenge is to achieve conventional starter performances with less copper volume.

A design procedure based on an optimization algorithm associated with an accurate magnetostatic model is developed to achieve this goal. A nonlinear permeance network model taking into account the three-dimensional aspects of the clawpole topology is developed for this purpose. It is then used in an optimization process in order to find the best claw-pole machine topology that can compete with the actual reinforced DC starters used in automotive Stop-Start systems.

\section{Claw-Pole DC Motor topology}

In order to evaluate the gain in term of copper volume provided by the claw-pole structure in comparison with conventional DC-series machines, only the stator is changed, while the rotor is kept identical between the two topologies. These two topologies are described in the following.

\subsection{Classical DC machine topology}

The conventional DC machine used in this application consists of a $2 p$ poles stator where each pole is separately wound around a solid iron tooth. The slotted rotor of such machines is generally provided with a simplex wave winding. On Fig. 1 , a picture of the stator and rotor of such machines is shown (case of $p=2$, and 19 rotor slots). The rotor currents are switched by means of a brush-collector system, on which the rotor winding is welded. In this machine, the axial length is approximately equal to the pole pitch - opening of the pole shoes - so the volume of the end-coils is approximately $50 \%$ 
of the copper volume used in the stator. Therefore, it is interesting to find a topology that reduces stator copper while maintaining equivalent performances.

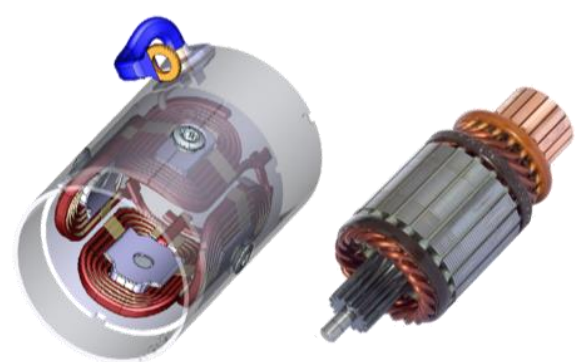

Fig. 1. Representation of the conventional DC machine

\subsection{Claw-Pole Topology}

The main idea of this paper is to replace the actual stator topology with a claw-pole stator while keeping the same rotor. In terms of performances, the objective is to reduce copper volume while maintaining equivalent torque density of the machine. The stator is made of two ferromagnetic parts and a circular excitation coil, as used in claw-pole synchronous machine. The advantage of such a topology is that there is no end-winding. Besides, the volume of the copper does not depend on the pole number. On Fig.2, a general representation of the topology is given in the case of a 6 poles machine.

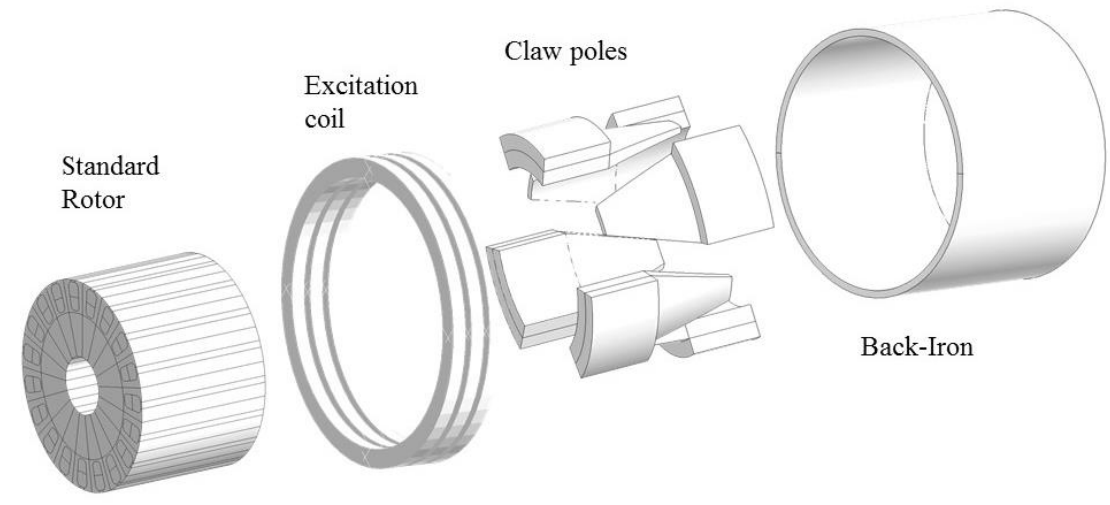

Fig. 2. Claw pole DC machine topology, a 6 poles case illustration.

In order to study the feasibility of this machine used as a starter in Stop-Start application, it is necessary to compare several variants in order to find the best structure that meets the performances with a significant reduction of copper volume. Several versions of claw-pole topology are presented below.

\subsection{Some claw-pole stator topologies}

The claw-pole architecture should present a kind of inhomogeneity of the flux density along the axial direction in case of axially-long machines. This may reduce its performance compared to conventional DC machines. Therefore, it is interesting to investigate the case of single-stack or multi-stack topologies in order to avoid such problems. On Fig. 3, the cases of single-stack and double-stack machines are presented.

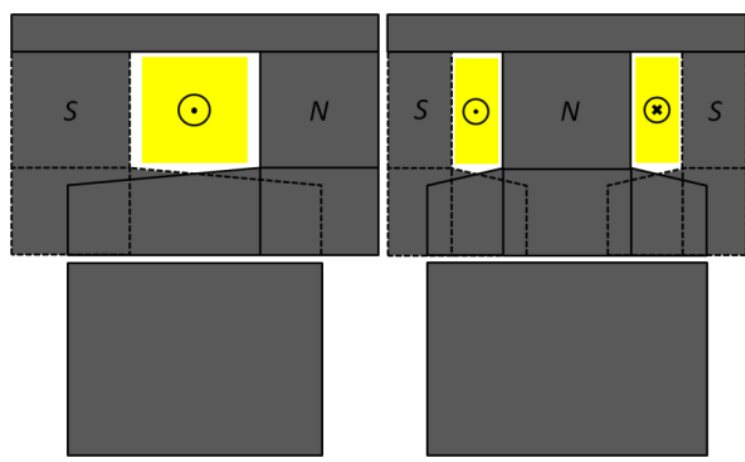

Fig. 3. Single-stack and double-stack stator claw-pole topologies 
Furthermore, two different dispositions of the stator poles involving two winding shapes are considered. In the first topology, the poles are non-overlapping, enabling the insertion of a cylindrical coil between two adjacent poles. In the second topology, the adjacent poles are overlapped, leaving no gap in the axial direction between the poles. This situation requires a wave-shape cylindrical coil enabling to bypass the poles. These two topologies are shown in Fig. 4.

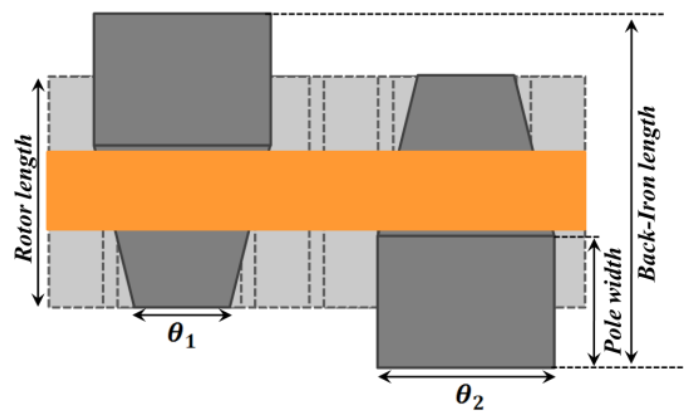

(a) Non-overlapping poles topology with cylindrical coil

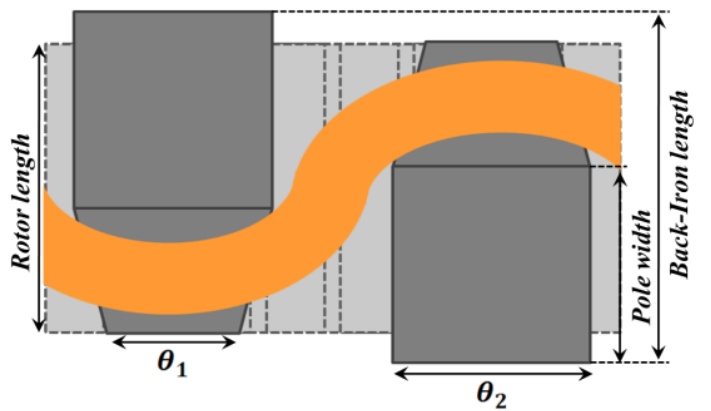

(b) Overlapping pole topology with wave-shaped coil

To compare standard machines of a 4 poles stator and two rotors with 19 and 21 slots respectively, many versions of claw-pole machines can be studied and designed. The results have to be compared to equivalent conventional DC machines. According to the well-known simplex wave winding rules for DC machines and some additional aspects concerning commutation, the different possibilities are gathered in Table I. For each The results have to be compared to equivalent conventional DC machines. According to the well-known simplex wave winding rules for DC machines and some additional aspects concerning commutation, the different possibilities are gathered in Table I. For each of these 4 cases, the single or double-stack structures with overlapping poles or not are also considered. Then all these variants represent 16 different machine versions that can be optimized and compared by means of Pareto fronts.

TABLE I. DIFFERENT POLARITIES FOR CLAW POLE MACHINES

\begin{tabular}{ccc}
\hline \hline CLASSICAL & $\begin{array}{c}4 \text { POLES / } 19 \\
\text { SLOTS }\end{array}$ & $\begin{array}{c}4 \text { POLES / } 11 \\
\text { SLOTS }\end{array}$ \\
\hline \hline CLACHINE & $\begin{array}{c}4 \text { POLES / } 19 \\
\text { SLOTS }\end{array}$ & $\begin{array}{c}4 \text { POLES / } 21 \\
\text { SLOTS }\end{array}$ \\
DC MACHINE & 6 POLES / 19 \\
SLOTS & $\begin{array}{c}\text { 8 POLES / } 21 \\
\text { SLOTS }\end{array}$ \\
\cline { 2 - 3 }
\end{tabular}

\section{Modeling}

The design of a claw-pole DC machine for its use in the Stop-Start starters requires the development of a fast-magnetic model suitable for an optimization process while taking into account high saturation levels and 3D effects.

In technical literature, analytical models dealing with claw-pole generators are proposed (Albert, 2004; Lim et al, 2008). These models are fast and take into account the 3D effects. However, they consider that the magnetic materials are supposed to have infinite magnetic permeability. Unfortunately, the DC-starters are magnetically stressed to provide a high torque density, thus causing a high saturation of the iron core. Therefore, the consideration of saturation is essential for a good design of the machine. In other words, such models are not suitable.

The use of 3D finite element models taking into account 3D effects and saturation is relevant for a precise design of a given machine. However, such models are time consuming. Optimization processes require a high number of performance evaluations, making 3D-FE models not suitable (Perez, 2013).

Analytical reluctance network based models combine the advantages of both previous models in terms of accuracy and fastness. This type of model is used for the design of the claw generator in many applications (Ostovic et al, 1989; Hecquet et al, 1998) and will be adopted in this paper to model claw-pole DC starters. 


\subsection{D-Permeance network Model}

In order to compare the 16 versions of claw-pole machines presented in Table 1 under the same conditions, a simplified reluctance model based on a single loop adapted to all topologies is presented in Fig. 5. It is a simplified model that allows to perform a pre-optimization in a very small CPU time. The geometrical parameters of the stator are clearly defined as well as the equivalent corresponding reluctance network. Since the geometry of the rotor is fixed in the optimization process, the rotor slots are not represented in this model.
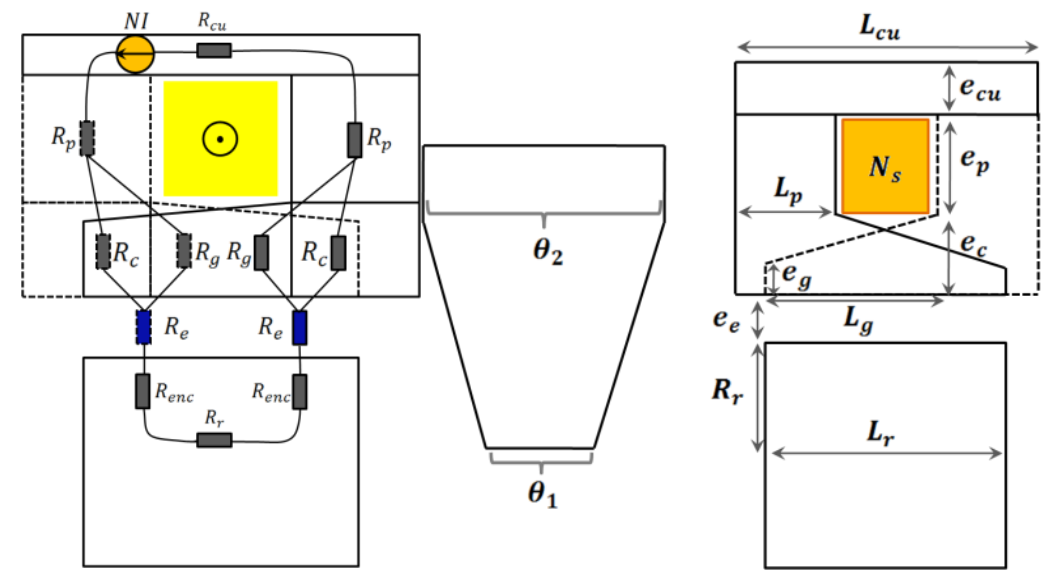

Fig. 5. Simplified representation of claw pole machine permeance model

For the final optimization step, a refined permeance model is required. For this purpose, a reluctance model has been developed in (Bazhar et al, 2015), in order to design and optimize a conventional DC machine used in the starter. It proves that taking into account the magnetic armature reaction is essential to the right modeling of such stressed machines. This model is improved to take into account the $3 \mathrm{D}$ aspects by considering many slices in the axial direction. Reluctances which model some regions of the claws depend on the real geometry of the corresponding portion of the claw. Fig. 6 . shows a schematic representation of the fine model over 2 poles, which will be used for the final optimization of the machine. This final permeance network is 3D and not easy to draw in a 2D scheme. It contains almost 150 permeances and magnetomotive forces (MMF) including both excitation and rotor armature reaction. Fig. 7. shows a 3D mesh of the stator geometry. This model is first validated with a 3D FE model with given geometrical parameters. Flux3D software is used for this purpose. 3,6 seconds are needed for one evaluation with the developed permeance model while 3D FE Models require 7 minutes using Flux3D in the same conditions.

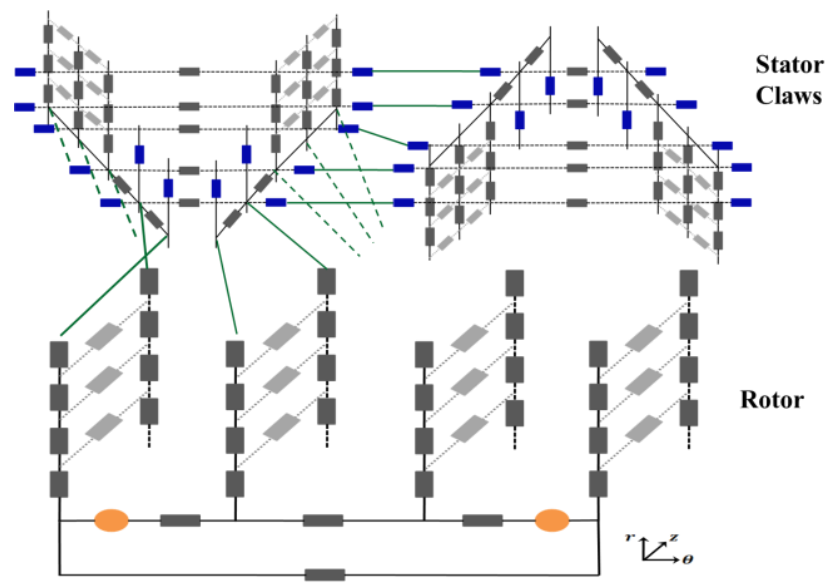

Fig. 6. Accurate permeance network of the DC claw-pole machine

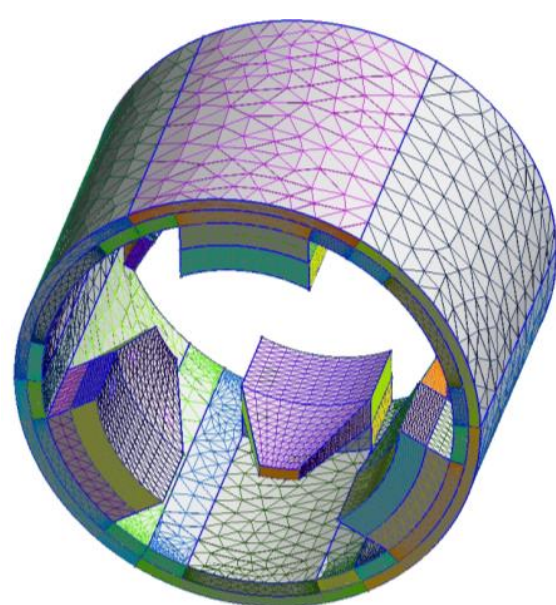

Fig. 7. The 3D FE model of the claw-pole stator 


\section{Optimizatin and design}

\subsection{Parameter pre-optimization}

The developed 3D permeance network is used to evaluate machine performances for a given geometry and supply. The main objective is to obtain with this claw topology the torque $\left(T_{m}\right)$ while minimizing the volume of copper $\left(V_{c u}\right)$ thanks to the cylindrical shape of the excitation coil.

The problem is very constrained because the rotor geometry is unchanged due to economic reasons. Only the geometry of the claw-pole stator is variable. In addition to that, the model is thermally constrained by a current density $(J)$ which is limited to a maximum value. Moreover, the voltage in this application is fixed to $12 \mathrm{~V}$ since the machine is directly powered by a $12 \mathrm{~V}$ battery. To limit copper losses in the machine and the starting voltage drop, the resistance $R$ of the equivalent circuit (stator and rotor are connected in series) is set to value $R_{0}$ fixed by the car manufacturers according to standards.

The developed permeance models are implemented as objective functions in a multi-objective optimization process using NSGAII algorithm. The optimization problem can be written as follows:

$$
\left\{\begin{array}{c}
\left(\max _{x \in D}(T) \min _{x \in D}\left(V_{c u}\right)\right) \\
\text { subject to: } J(x)<J_{\max } \text { and } R(x)=R_{0} \\
\text { with: } x=\left[e_{g}, e_{c}, e_{p}, e_{c u}, L_{p}, L_{g}, \theta_{1}, \theta_{2}, N_{s}\right]
\end{array}\right.
$$

In a first step, the simplified model is used to compare the 16 versions of the claw-pole machine. An optimization process evaluating 20000 times the defined objectives using 200 individuals that evolve during 100 iterations. By comparing the machines presented in Table I, for a single-stack stator with non-overlapping poles, the Pareto front of Fig. 8 (a) is obtained.

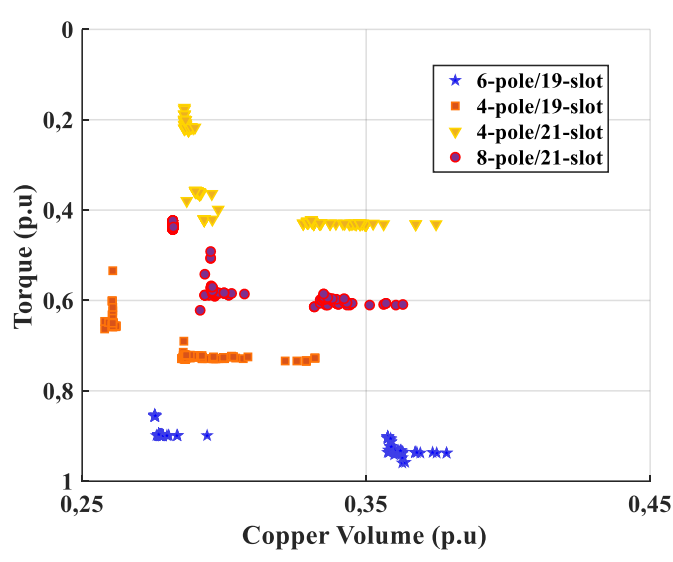

(a) Single-stack non-overlapping

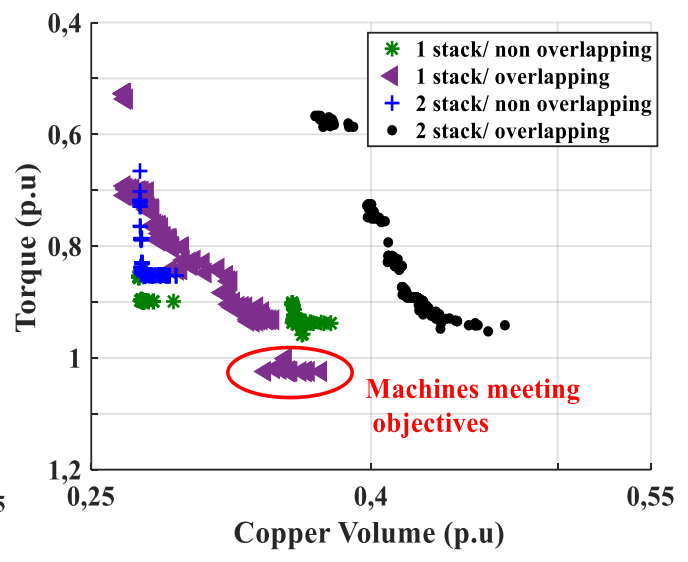

(b) 6 poles stator topologies

Fig. 8. Pareto Fronts of problem (1)

On the previous figures, the torque and the copper volume are displayed in per-unit (p.u.) in order to compare clawpole machines with the standard DC motor $\left(T=1\right.$ p.u and $V_{c u}=1$ p.u. $)$. According to these figures, the 6 poles $/ 19$ slots machine is clearly the best in terms of torque density. Indeed, the torque increases with the number of poles, thanks to the use of claw-pole topology. However, 8 poles / 21 slots machines are less efficient because of the commutation. Indeed, 21 slots rotors are not suitable for 8 poles. When the number of slots on the rotor is maintained and the number of poles is increased, the switching time ratio of the rotor currents increases and exceeds $50 \%$ in this case. Such a situation strongly reduces the torque.

\subsection{Optimization refinement and prototype construction}

The case of a 6 poles / 19 slots machine is considered in the following. Four versions of the stator are considered. They combine the cases of: 1 or 2 stacks on one hand, and overlapping or non-overlapping poles on the other hand. The corresponding Pareto fronts are shown on Fig. 8 (b). It can be clearly seen that the single-stack with overlapping poles presents the best compromise between torque increase and copper reduction. The corresponding group of individuals is highlighted on the same figure. This result can be justified by the fact that the single-stack version presents a higher cross 
section of the core compared to the double-stack version. This makes the equivalent reluctance lower, thus increasing the flux.

Consequently, the 6 poles / 19 slots machine with a single-stack rotor and overlapped poles is the best machine topology in terms of torque (greater than 1 p.u) and copper volume (less than 1 p.u).

In order to dig deeper in the optimization of this topology while taking into account the magnetic armature reaction that impacts the torque, the second reluctance model shown on Fig. 6 will be used in the optimization process carried out on the selected topology.

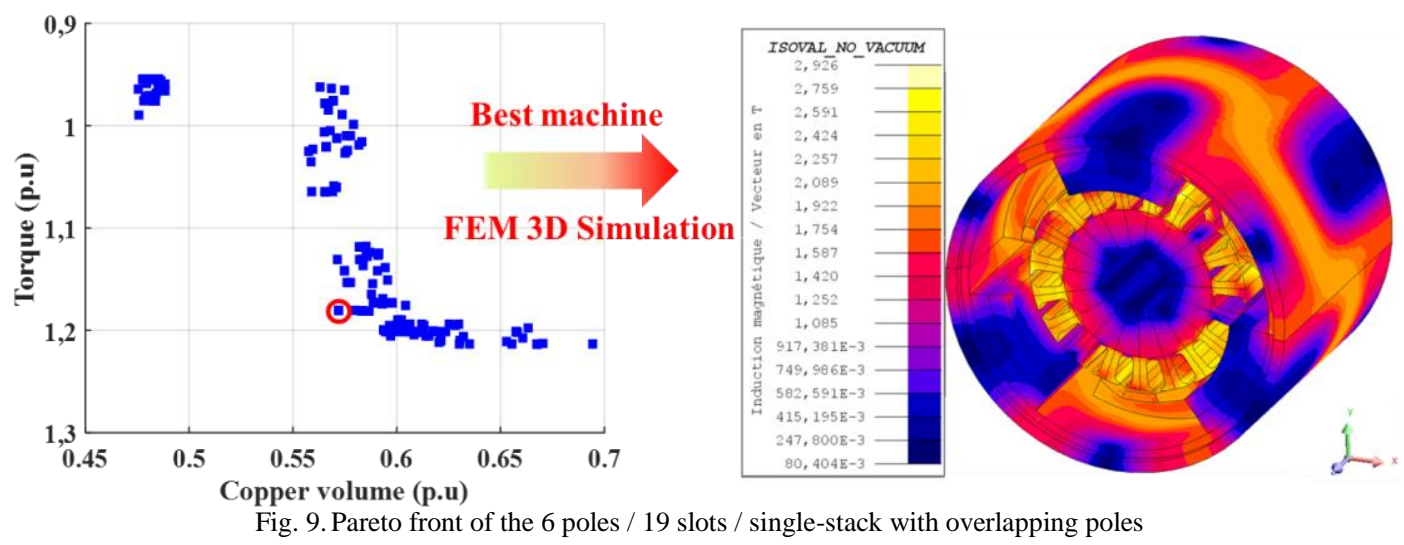

The new optimization uses the finest model and requires 20000 evaluations with 200 generations with NSGA II algorithm to solve the problem (1).

The Pareto front of the 6 poles / 19 slots single-stack machine with overlapped poles is shown on Fig. 10. It can be noticed that it allows to obtain several machines satisfying the torque criterion $(T>1 p . u$. $)$ with a high copper gain. The machine represented in red on Fig. 9 is selected to be prototyped. It provides a torque of $T>1.1 p$. $u$. and a copper reduction of $42 \%$. Conversely, it presents a $15 \%$ increase of iron volume compared to the conventional machine. Before prototyping this machine, a full 3D finite element simulation is performed and results are compared to those provided by the reluctance model, (Fig. 10 (a)). Both models provide similar results in terms of torque-current curve, even for highly saturated operation points. This confirms that the optimization process using the reluctance model provides good results.

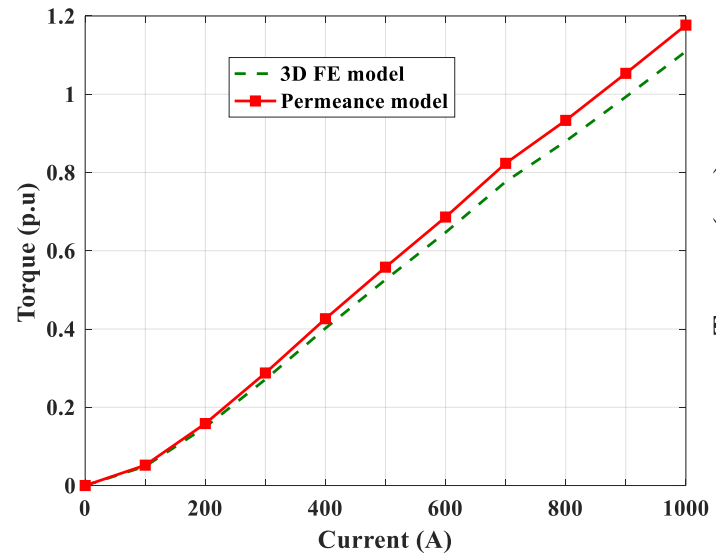

(a) Simulation

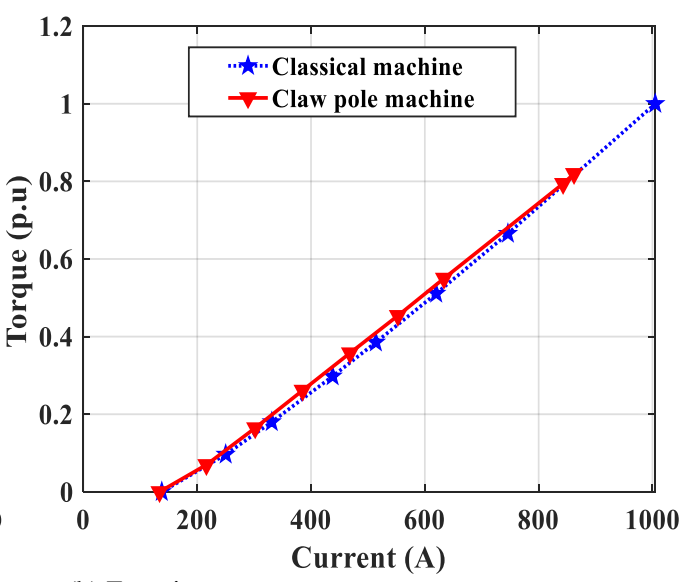

(b) Experiments

Fig. 10. Torque-current curves of both machines

The 6 claw-poles optimized machine is prototyped with a special shape of the winding and tested on a bench to measure its characteristics. On the same bench, the conventional 4-pole DC machine is tested in the same conditions. Both machines give the same torque-current curves (Fig.10 (b)). The advantage of the claw-pole machine consists in saving almost $42 \%$ in terms of copper volume in the stator. Indeed, the optimization is mainly performed in terms of 
copper saving rather than in torque increasing. In Fig. 11.(a), a picture of the stator claw-pole armature manufactured is shown, as well as the whole final prototype.

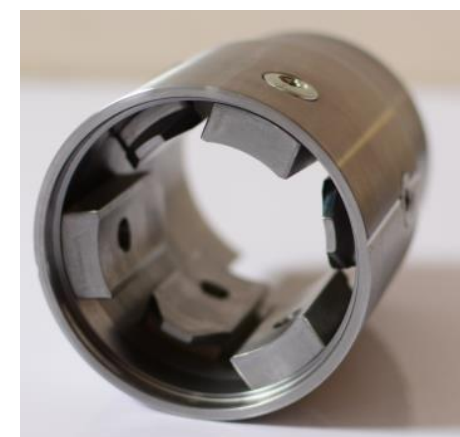

(a) Claw-pole stator armature

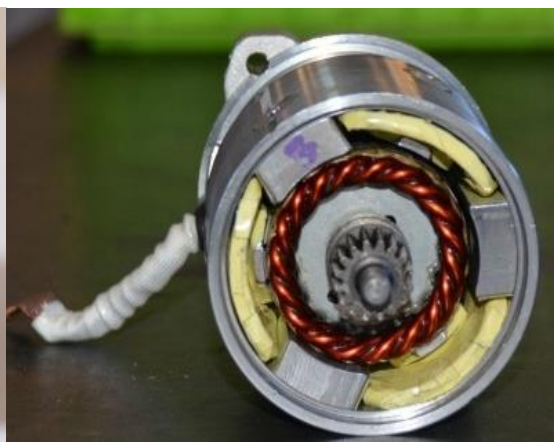

(b) Whole claw-pole prototype

Fig. 11. The claw-pole DC machine manufactored prototype

\section{Conclusion}

In this paper, the authors have investigated the possibility of using the claw-pole principle on DC machines for Stop-Start starters in micro-hybrid vehicles. The roadmap is the reduction of copper volume. Special reluctance network models are developed for this purpose and optimization processes are performed. Following this optimization process, a prototype is manufactured and tested. It gives similar performances as the standard conventional DC machine with a gain of $42 \%$ in terms of copper volume used in the stator.

\section{REFERENCES}

A. M. EL-Refaie, et al. "Rotor End Losses in Multiphase Fractional-Slot Concentrated-Winding Permanent Magnet Synchronous Machines", in IEEE Transactions on Industry Applications, vol. 47, no. 5, pp. 2066-2074, Sept.-Oct. 2011.

C. M. Spargo, B. C. Mecrow, J. D. Widmer, C. Morton, "Application of Fractional-Slot Concentrated Windings to Synchronous Reluctance Motors," in IEEE Transactions on Industry Applications, vol. 51, no. 2, pp. 1446-1455, March-April 2015.

C. Espanet, "Modélisation et conception optimale de moteurs sans balais à structure inversée. Application au moteur roue (French), Modeling and optimal Design of brushless motors with reversed architecture (english) ", PhD Dissertation, Université de Franche-Comté, 1999.

J. Cros, P. Viarouge, A. Halila, "Brush DC motors with concentrated windings and soft magnetic composites armatures", Conference Record of the 2001 IEEE Industry Applications Conference. 36th IAS Annual Meeting (Cat. No.01CH37248),, Chicago IL, USA, 20

R. Rebhi, A. Ibala, A. Masmoudi, "An attempt to improve the sizing of a hybrid excited brushless claw pole alternator", COMPEL - The international journal for computation and mathematics in electrical and electronic engineering, Volume: 32 Issue: 1, 2012

R. Felicetti, I. Ramesohl, "Design of a mass-production low-cost claw-pole motor for an automotive application", COMPEL - The international journal for computation and mathematics in electrical and electronic engineering, Volume: 22 Issue: 4, 2003

L. Albert, "Modélisation et optimisation d'un alternateur à griffes appliqué aux systèmes automobile (French), Modelling and optimization of claw pole alternators applied to automotive systems (English)", PhD Dissertation, National Polytechnic Institute of Grenoble, France, 2004.

S.-B. Lim, I.-S. Jung, Y.-K. Kim, J.-H. Choi et B.-G. Gu, "Analysis of claw-pole machine using magnetic circuit method applying Fourier series", International Conference on Electrical Machines and Systems, Wuhan, 2008.

S. Perez, "Contribution au dimensionnement optimal d'alternateur à griffes sans aimants - Apport des alliages FeCo (French), Contribution to the optimal design of a magnetless claw-pole alternator : Impact of FeCo Alloys use", PhD Dissertation Université de Grenoble, 2013.

V. Ostovic, J. M. Miller, V. Garg, R. D. Schultz, S. Swales, "A magnetic equivalent circuit based performance computation of a Lundell alternator", Conference Record of 1998 IEEE Industry Applications Conference. Thirty-Third IAS Annual Meeting (Cat. No.98CH36242), vol.1, St. Louis, MO, USA, 1998

M. Hecquet et P. Brochet, "Time variation of forces in a synchronous machine using electric coupled network model", IEEE Transactions on Magnetics, vol. 34, n 15, pp. 3214-3217, Sep 1998.

S. Bazhar, J. Fontchastagner, N. Takorabet, N. Labbe and R. Andreux, "Torque modeling and optimization of DC machine based on reluctance network taking into account armature reaction magnetic field", 2015 18th International Conference on Electrical Machines and Systems (ICEMS), Pattaya, 2015, pp. $1580-1586$ 